molodshoho shkilnoho viku $v$ umovakh Novoi ukrainskoi shkoly [Tasks of social and pedagogical work with primary school students in the New Ukrainian school.]. Sotsiolohiia ta sotsialna robota $v$ umovakh natsionalnykh ta rehionalnykh vyklykiv: materialy dopovidei ta povidomlen Mizhnarodnoi naukovo-praktychnoi konferentsii. Red. I.V. Kozubovska, F.F. Shandor. Uzhhorod: TOV «RIK-U». 100-102 [in Ukrainian].

УдК 378.046.4: 373.58/.5.091.2.011.3-051:51]:004

DOI: https://doi.org/10.35387/od.2(18).2020.122-130

Шишкіна Марія Павлівна - доктор педагогічних наук, старший науковий співробітник, завідувач відділу хмаро орієнтованих систем інфоорматизації освіти Інституту інфрормаційних технологій $і$ засобів навчання НАПН України

ORCID iD: $h$ ttp://orcid.org/0000-0001-5569-2700

E-mail: shyshkina@iittt.gov.ua

\title{
ОРГАНІЗАЦІЯ НАВЧАЛЬНОГО Й НАУКОВОГО СПІВРОБІТНИЦТВА У ВІРТУАЛЬНИХ СИСТЕМАХ ВІДКРИТОЇ НАУКИ У ЗАКЛАДАХ ВИЩОЇ ОСВІТИ
}

\begin{abstract}
Анотація. У статmі розглянуто особливості фрормування віртуальних систем відкритої науки у закладах вищої освіти, що $\epsilon$ суттєвою передумовою підготовки IКТ-компетентних фрахівців, здатних до активного, доцільного, науково обгрунтованого застосування найсучасніших IKT у своїй профресійній діяльності. У результаті дослідження уточнено поняттєвий апарат; виявлено перспективи та сучасні європейські тенденції формування хмаро орієнтованих систем відкритої науки у закладах вищої освіти; визначено перспективні шляхи застосування хмаро орієнтованих платорорм $і$ адаптивних сервісів управління контентом у діяльності викладавча, науковия; узагальнено досвід впровадження окремих сервісів хмаро орієнтованих систем відкритої науки у процесі підтримування наукового співробітництва у закладах вищої освіти. Встановлено, що завдяки ширшому залученню в освітній у процес закладів вищої освіти засобів і сервісів науково-освітніх хмаро орієнтованих платформ, а також різних типів корпоративних хмарних сервісів вдається досягти позитивних змін у здійсненні навчальної $і$ наукової діяльності, поліпшенні ї якісних $і$ кількісних показників, застосуванні нових фрорм і моделей ї̈ організації, що позитивно впливає як на результати навчання, так $і$ на розвиток наукових досліджень, поліпшення рівня їх організації, підвищення ефективності. Узагальнено досвід використання відкритих хмаро орієнтованих систем відкритої науки для підтримування комунікації; спільної роботи; адаптивного управління контентом; створення $i$
\end{abstract}


використання електронних освітніх ресурсів у процесі організації освітньо-наукового співробітництва у віртуальних міжнародних колективах, створених на базі декількох закладів вищої освіти.

Ключові слова: відкрита наука; системи відкритої науки; віртуальні колективи; інструменти відкритої науки; заклади вищої освіmu.

Shyshkina Mariya - Doctor of Pedagogical Sciences, Senior Researcher, Head of the Department of Cloud-Oriented Systems of the Education Informatization Institute of Information Technologies and Learning Tools of the NAES of Ukraine

ORCID iD: http://orcid.org/0000-0001-5569-2700

E-mail:shyshkina@iittt.gov.ua

\section{ORGANIZATION OF EDUCATIONAL AND RESEARCH COOPERATION IN VIRTUAL SYSTEMS OF OPEN SCIENCE IN HIGHER EDUCATION INSTITUTIONS}

Abstract. The article considers the peculiarities of the formation of virtual open science systems in higher education institutions, which is an essential prerequisite for training ICT-competent professionals capable of active, appropriate, scientifically sound use of modern ICT in their professional activities. As a result of the research the conceptual apparatus is specified; the prospects and modern European tendencies of formation of cloud-oriented systems of open science are revealed; the promising ways to use cloud-based platforms and adaptive content management services to support the activities of a scientist identified; the experience of introduction of certain services of open science cloud-based systems in activity of a research group in higher education institution is generalized. It is established that due to wider involvement of tools and services of scientific and educational cloud-based platforms, as well as various types of corporate cloud services to support learning and research processes it is possible to achieve positive changes in this activity, improve its qualitative and quantitative indicators, introduce new forms and models of its organization. It has a positive effect on both learning outcomes and the development of scientific research, improving the level of their organization, increasing efficiency. The experience of using open cloud-based systems of open science to maintain communication; joint work; adaptive content management; creation and use of electronic educational resources in the process of organizing educational and scientific cooperation in virtual teams established in different higher education institutions is generalized.

Key words: open science; open science systems; virtual teams; open science tools; higher education institutions.

Постановка проблеми, її актуальність. Формування у закладах 
освіти (ЗВО) високотехнологічного освітньо-наукового середовища $\epsilon$ суттєвою передумовою підготовки ІКТ-компетентних фахівців, здатних до активного, доцільного, науково обґрунтованого застосування хмарних технологій у своїй професійній діяльності. Завдяки використанню хмарних технологій виникає можливість побудови більш зручних, гнучких, масштабованих систем організації доступу до електронних ресурсів і сервісів у процесі навчання і наукових досліджень, створюються умови для колективної роботи з програмними додатками зі зняттям географічних і часових обмежень, більш широкої реалізації принципів відкритої освіти і науки. У зв'язку з цим, необхідно обґрунтування теоретико-методологічних засад створення хмаро орієнтованих систем відкритої науки у закладах освіти, дослідження поняттєвого і концептуального апарату, моделей, принципів, підходів і методів їх організації і розвитку, визначення найбільш доцільних шляхів проєктування і використання у межах цих систем різних видів хмарних сервісів та інструментів.

Аналіз останніх досліджень і публікацій. Підхід, що ґрунтується на технології хмарних обчислень, дає нове бачення розвитку галузі адаптивного навчання і досліджень, завдяки удосконаленню підходів штучного інтелекту та інструментів інформаційно-комунікаційних мереж, що утворює нову тенденцію розвитку освітньо-наукового середовища закладів вищої освіти (Charband, Nima, 2018). Адаптивні хмарні платформи стають новим етапом у розвитку хмаро орієнтованих систем, що мають високий потенціал та значні перспективи для використання у закладах вищої освіти. Тож особливу увагу слід приділити використанню адаптивних хмарних платформам для підтримки процесів спільного навчання та досліджень.

Принципи і концептуальні засади відкритої науки висвітлено у міжнародних документах, що стосуються особливостей формування Європейського дослідницького простору, концепції відкритої науки (Open Science, 2015; European Cloud Initiative - Building a competitive data and knowledge economy in Europe, 2016; Open science monitor, 2020). Науковометодологічні питання створення та розвитку хмаро орієнтованого освітньо-наукового середовища закладу вищої освіти в контексті пріоритетів відкритої науки розглянуто у (Bykov, Shyshkina, 2018). Питання формування і розвитку кометентностей відкритої науки у процесі навчання і підготовки наукових, науково-педагогічних кадрів висвітлено у (Providing researchers with the skills and competencies they need to practise Open Science, 2017; Schmidt, et al, 2016). Особливої актуальності набуває вивчення проблем формування віртуальних систем відкритої науки у ЗВО, запровадження у практику навчання й досліджень принципів відкритої науки, створення відкритих освітньо-наукових середовищ.

Мета статті - проаналізувати, узагальнити досвід і результати використання інструментів і сервісів адаптивних хмаро орієнтованих систем відкритої науки для підтримки процесів міжнародного наукового 
співробітництва у закладах вищої освіти, зокрема на основі результатів проєкту V4 + ACARDC.

Виклад основного матеріалу дослідження. Хмарна платформа підтримування навчання та наукових досліджень розглядається як набір хмаро орієнтованих інструментів для здійснення різних навчальних та дослідницьких заходів. В рамках однієї платформи може бути інтегровано багато різних інструментів, що забезпечують більше можливостей для реалізації відкритого та адаптивного навчання та досліджень.

Віртуальний колектив проєкту - це колектив або спільнота учасників (дослідників), які здійснюють проєктну діяльність (зокрема, комунікації) відповідно до спільно визначених цілей. Стійка інформаційна підтримка життєвого циклу проєкту та інформаційно-технологічна інтеграція управління проєктами забезпечується за допомогою засобів, заснованих на IKT.

Адаптивна хмаро орієнтована система відкритої науки - це хмаро орієнтована система (яка ґрунтується на хмарній платформі), що за своїми параметрами може автоматично налаштовуватися у відповідності до цілей і завдань організації процесу наукового співробітництва, різних індивідуальних особливостей та освітньо-наукових потреб учасників віртуального дослідницького колективу, що може бути сформований, зокрема, на базі закладів вищої освіти. Хмарні технології забезпечують реалізацію базових характекристик організації освітньо-наукового середовища, а саме: відкритість та гнучкість (Bykov, Shyshkina, 2018). Якщо змінюються цілі й завдання розвитку середовища, можливо адекватно змінювати його інструменти, а також загальний склад і структуру, модернізувати методи їх використання. Отже, структуру та склад можна узгодити з запланованими цілями розвитку та новими викликами, які можуть з'явитися в майбутньому.

У зв'язку з цим дослідження різноманітних засобів та інструментів формування хмаро орієнтованих віртуальних систем відкритої науки для підтримування процесів міжнародного наукового співробітництва у закладах вищої освіти потрапляє у центр уваги досліджень проєкту «V4 + Academic Research Consortium Integrating Databases, Robotics and Language Technologies (V4 + ACARDC)» - академічний дослідницький консорціум з інтегрування баз даних, робототехніки і мовних технологій), заснованого у 2018 р. за підтримки Вишеградського фонду (Visegrad Fund, https://www.visegradfund.org/). Інститут інформаційних технологій і засобів навчання НАПН України став одним із партнерів цього міжнародного проєкту, до складу якого входять представники шістьох закладів вищої освіти зі Словаччини, Угорщини, Чехії, Польщі та України.

Метою проєкту постало вирішення низки питань, пов'язаних із пріоритетними напрямами застосування ІКТ для підтримування регіонального співробітництва в ЄС, зокрема: використання ІКТ пошуку партнерів для виконання програми Horizon 2020; цифрових платформ 
майбутнього; подолання мовних бар'єрів; вдосконалення навчання й розширення масштабів інформатизації освітнього процесу; дослідження та збереження наукової та культурної спадщини та інших. Серед пріоритетних завдань проєкту - вивчення можливостей використання регіональної платформи для інтеграції та розгортання різних типів сервісів для навчання та досліджень, таких як навчальні роботи, сервіси опрацювання різних типів даних, зокрема текстів тощо. Визначення складу та інтеграція різних сервісів опрацювання даних у межах зазначеної платформи постало одним із напрямів наукових досліджень у межах зазначеного проєкту.

Серед основних результатів проєкту V4 + ACARDC виокремимо створення хмаро орієнтованої системи IT-підтримки дослідницької діяльності віртуального наукового колективу, яка складається з мережної IKT інфраструктури, навчального програмного забезпечення WPadV4 та методики створення навчальних пакетів та супутніх навчальних матеріалів і їх багатомовної підтримки. Опрацювання знань і контекстно керованих таблиць даних виконується додатком бази даних WPadV4, автор C. Свецький (Svetsky, Moravcik, 2016). Оскільки це програмне забезпечення засноване на абстрагуванні метаданих та контенту, воно дозволяє користувачам обробляти будь-який контент у структурі за замовчуванням. Таким чином, користувач може створювати таблиці знань для побудови навчальних текстів, матеріалу для лекцій і вправ. 3 точки зору опрацювання людиною, подання знання відбувається за допомогою блоків метаданих та контенту, в які користувач може вставити свій текст або текст взагалі будь-який текст ASCII. Викладач може вставляти будь-які навчальні матеріали чи текст безпосередньо у віртуальні таблиці знань за допомогою звичайної мови без необхідності використання інших машинних мов. У цьому випадку за допомогою метаданих ідентифікують зміст, який складається у вигляді тексту, написаного вручну. Таблиці WPadV4 можуть бути використані для підтримування будь-яких видів діяльності, наприклад: проєктування пакетів навчальних матеріалів, створення інформаційних таблиць або таблиць науково-технічних даних, формування таблиць пошуку, створення навігаційних таблиць, створення персональних таблиць для дозвілля, конспектів, організаційного призначення, особистих календарів, таблиці організації самонавчання, таблиці підтримування електронного навчання, багатомовні таблиці (словники, фрази, ...), таблиці управління файлами тощо.

Прикладне програмне забезпечення WPadV4 було встановлене на віртуальних робочих столах 3 Windows 10 для десяти комп'ютерів дослідників і партнерів проєкту. Бета-версія WPadV4 є базовим рішенням для навчального робота / персональної системи організації управління контентом. Цей засіб також можна використовувати на мобільному додатку (що містить модуль озвучування тексту) для Android. 3 моменту усвідомлення важливості віртуальних таблиць знань дослідження авторів були більш систематично зосереджені на побудові освітньої технології на 
основі знань, що складається з навчального програмного забезпечення та онлайн / офлайн-інфраструктури, що містить сховища знань експертів та мовні та освітні пакети. Це додатково охоплює вирішення проблем віртуального подання знань та передачі файлів навчального контенту у межах діючої інфраструктури. Моделювання цих елементів у спільноті дослідників («спільнота інноваторів») пояснюється через проєктування використання хмарного сервісу та віддаленого робочого столу.

Було розроблено пілотну систему IT підтримки, яка містить, зокрема, такі елементи, як:

а) спільна IКТ-інфраструктура, яка дає змогу всім партнерам V4 + отримувати доступ та здійснювати спільну діяльність зі своїх персональних чи робочих комп'ютерів чи навчальних аудиторій (хмарні обчислення, віртуальні машини та система веб-сторінок);

б) методика проєктування та напівавтоматичного виготовлення навчальних пакетів, бібліотек, наукових сервісів, системи пошуку 3 використанням багатофункціонального програмного забезпечення WPadV4, яке було розвинуто в межах проєкту;

в) вказівки щодо того, як забезпечити багатомовну підтримку IT на мовах V4 +, яка поєднана з англійською мовою (ця підтримка є важливою для написання наукових робіт, а також для розроблення та спільної підготовки навчальних текстів V4 + для підтримки побудови академічних курсів англійською).

Результат, розроблений у проєкті: Віртуальний робочий простір на базі віртуальної машини з Windows 10 - у вигляді віддаленого робочого столу. Це означає, що всі партнери мають однаковий комп'ютер (з доступом через пароль). Це було потрібно для розроблення та тестування програмного забезпечення WPadV4 для виробництва програмних продуктів, наприклад, навчальних пакетів. Хмарна платформа була використана для стійкої інформаційної підтримки життєвого циклу проєкту відповідно до спільно визначених цілей та інформаційно-технологічної інтеграції управління проєктом. Платформа виявилася придатною для задоволення цих потреб та працювати над завданнями узгоджено та в інтуїтивно зрозумілому інтерфейсі.

Принципів і пріоритетів відкритої науки було дотримано завдяки використанню хмарної платформи навчання та досліджень для підтримки процесів співпраці. Передусім йдеться про комунікацію, пошук інформації, дослідження даних, обмін результатами та методами, управління контентом, оскільки всі необхідні матеріали, такі як інструктивні матеріали, статті, навчальні матеріали, колекції документів тощо, наразі підтримуються та доступні на платформі. Адаптивне управління контентом підтримувалося дослідницьким інструментом WPadV4, який використовувався для обробки доступних даних на базі стійкої моделі. Таким чином, усі дані, зібрані в ході дослідження, були обґрунтованими, сумісними й доступними для багаторазового використання для всіх 
партнерів. Це повинно було забезпечити відкритість і гнучкість процесів наукового співробітництва.

Висновки і перспективи подальших досліджень. Встановлено, що завдяки більш широкому залученню в освітньо-науковий процес закладів вищої освіти засобів і сервісів хмаро орієнтованих платформ, а також різних типів корпоративних хмарних сервісів вдається досягти позитивних змін у здійсненні цієї діяльності, поліпшенні її якісних і кількісних показників, застосуванні нових форм і моделей її організації, що позитивно впливає як на результати навчання, так і на розвиток наукових досліджень, підвищення її ефективності тощо. Узагальнено досвід використання хмаро орієнтованих інструментів відкритої науки для підтримання процесів міжнародного наукового співробітництва у закладах вищої освіти: науково-освітніх інформаційних мереж відкритої науки; комунікації; спільної роботи; адаптивного управління контентом; підтримання процесів створення й використання електронних освітніх ресурсів у процесі організації освітньо-наукового співробітництва у віртуальних колективах. Навчальний компонент із програмним забезпеченням WPadV4 був розроблений та протестований на основі хмарного серверу, розгорнутого на базі AWS (Amazon Web Services). Це відкриває шлях до розроблення методів розгортання компонентів навчального і наукового призначення в освітньо-науковому середовищі закладів вищої освіти. Питання вибору та інтеграції сервісів, вивчення різних їх компонентів, а також найбільш доцільних шляхів застосування у системах відкритої науки, поєднання інтелектуальних технологій і мережних хмарних сервісів складає перспективу для подальших наукових досліджень.

\section{Список використаних джерел}

Bykov, V., Shyshkina, M. (2018). The conceptual basis of the university cloudbased learning and research environment formation and development in view of the open science priorities. Information Technologies and Learning Tools, $68(6)$.

URL: https://journal.iitta.gov.ua/index.php/ittt/article/view/2609/1409

Charband, Y., Nima Jafari Navimipour. (2018). Knowledge sharing mechanisms in the education: A systematic review of the state of the art literature and recommendations for future research. Kybernetes, 47(7), 14561490.

European Cloud Initiative - Building a competitive data and knowledge economy in Europe. (2016). Communication from the Commission to the European Parliament, the Council, the European Economic and Social Committee and the Committee of the Regions. Brussels, 19.4 .2016$.

URL:

http://eur-lex.europa.eu/legalcontent/EN/TXT/PDF/?uri=CELEX:52016DC0178\&from=EN

Open science monitor. (n. d.). (2020). Retrieved October 19, 2020. URL: https://ec.europa.eu/info/research-and-innovation/strategy/goals- 
research-and-innovation-policy/open-science/open-science-monitor_en Open Science. (2015). Policy Brief, December, 2015. URL: https://docs.google.com/viewer?a=v\&pid=sites\&srcid=ZGVmYXVsdGR vbWFpbnxlcmF1a3JhaW5IfGd4Ojc1Mjk0ZTg1NTA2MmQyNDg

Providing researchers with the skills and competencies they need to practise Open Science. (2017). European Union. DOI:10.2777/121253.

Schmidt, B., Orth, A., Franck, G., Kuchma, I., Knoth, P., \& Carvalho, J. (2016). Stepping up Open Science Training for European Research. Publ., 4, 16.

Shyshkina, M. (2018). The General Model of the Cloud-based Learning Environment of Educational Personnel Training. Teaching and Learning in a Digital World. ICL 2017. Advances in Intelligent Systems and Computing, 715. Springer, Cham.

Svetsky, S., Moravcik, O. (2016). The empirical research on human knowledge processing in natural language within engineering education. WEEF\& GEDC 2016: The world engineering education forum \& The global engineering deans council, 10-12. Seoul, Korea.

\section{References (translated and transliterated)}

Bykov, V., Shyshkina, M. (2018). The conceptual basis of the university cloud-based learning and research environment formation and development in view of the open science priorities. Information Technologies and Learning Tools, 68(6). URL: https://journal.iitta.gov.ua/index.php/itt/article/view/2609/1409 [in English].

Charband, Y., Nima Jafari Navimipour. (2018). Knowledge sharing mechanisms in the education: A systematic review of the state of the art literature and recommendations for future research. Kybernetes, 47(7), 1456-1490 [in English].

European Cloud Initiative - Building a competitive data and knowledge economy in Europe. (2016). Communication from the Commission to the European Parliament, the Council, the European Economic and Social Committee and the Committee of the Regions. Brussels, 19.4.2016. URL: http://eurlex.europa.eu/legalcontent/EN/TXT/PDF/?uri=CELEX:52016DC0178\&from=EN [in English].

Open science monitor. (n.d.). (2020). Retrieved October 19, 2020. URL: https://ec.europa.eu/info/research-and-innovation/strategy/goals-researchand-innovation-policy/open-science/open-science-monitor_en [in English].

Open Science. (2015). Policy Brief, December, 2015. URL: https://docs.google.com/viewer?a=v\&pid=sites\&srcid=ZGVmYXVsdGRvb WFpbnxlcmF1a3JhaW5IfGd4Ojc1Mjk0ZTg1NTA2MmQyNDg [in English].

Providing researchers with the skills and competencies they need to practise Open Science. (2017). European Union. DOI:10.2777/121253 [in English].

Schmidt, B., Orth, A., Franck, G., Kuchma, I., Knoth, P., \& Carvalho, J. (2016). Stepping up Open Science Training for European Research. Publ., 4, 16 [in English]. 
Shyshkina, M. (2018). The General Model of the Cloud-based Learning Environment of Educational Personnel Training. Teaching and Learning in a Digital World. ICL 2017. Advances in Intelligent Systems and Computing, 715. Springer, Cham [in English].

Svetsky, S., Moravcik, O. (2016). The empirical research on human knowledge processing in natural language within engineering education. WEEF\& GEDC 2016: The world engineering education forum \& The global engineering deans council, 10-12. Seoul, Korea [in English]. 